\title{
Türk İmalat Sanayinde İhracat ve İnovasyon Arasındaki İlişki*
}

\author{
Selçuk PERÇIN ${ }^{1}$ \\ Aykut KARAKAYA ${ }^{2}$ \\ Seymur AĞAZADE ${ }^{3}$
}

ÖZ: Posner'in (1961) “teknoloji açı̆̆l teorisi” ve Vernon'un (1966) “ürün dönemleri teorisi”" inovasyonun piyasa gücüne neden olduğunu ve ihracatı kolaylaştırdığını öngörür. Diğer yönden ihracatçı firmalar, performanslarını artırıcı yönde etkileyen inovasyon sürecine daha yoğun şekilde maruz kalırlar. Bu teorik yaklaşımlar ihracat ve inovasyon arasındaki nedensellik ilişkisinin yönü hakkında farklı öngörülerde bulunurlar. Bu araştırma 2008-2013 dönemleri itibariyle Türk Imalat Sanayii endüstri kollart için ihracat yoğunluğu ve ar-ge yoğunluğu arasındaki ilişkiyi incelemektedir. Araştırma analiz yöntemi İki Aşamalı Sistem Genelleştirilmiş Momentler Metodudur. Araştırmada nedensellik ilişkisi iki modelle ifade edilmiş ve Wald Testine dayanarak incelenmiştir. Birinci model olan ihracat modelinin bă̆ımsız değişkenleri ar-ge yoğunluğu ve reel döviz kuru endeksidir. Ar-ge modelinin bă̆ımsız değişkenleri ise, ihracat yoğunluğu ve rekabet düzeyini gösteren Herfindahl-Hirsckman Endeksidir. Elde edilen bulgular sonucunda ar-ge yoğunluğundan ihracat yoğunluğuna doğru tek yönlü nedensellik ilişkisi olduğu bulunmuştur. Bu sonuç Posner'in (1961) “teknoloji açı̆̆l teorisi” ile Vernon'un (1966) “ürün dönemleri teori”'lerinin inovasyon ve ihracata ilişkin öngörülerinin Türk Imalat Sanayi'nde geçerli olduğunu desteklemektedir.

Anahtar Kelimeler: İmalat Sanayi, İnovasyon, İhracat, Panel Veri Analizi

JEL Sinıflandırılması: L60, O30, F10, C33

\section{The Relationship between Export and Innovation in Turkish Manufacturing Industry}

\begin{abstract}
Posner's (1961) “technological gap theory" and Vernon's (1966) "product life cycle theory" predicts that innovation causes market power and facilitates export. In other side export encourages firms and provides more affirmative environment for innovative processes. These theoretical approaches have different predictions regarding the direction of causality between export and innovation. Using Two-Step System Generalized Moments of Method this study investigates causality relationship between export intensity and $R \& D$ intensity for the period 2008 2013 in Turkish Manufacturing Industry. Causality relationship was modeled within two different equations and analyzed by Wald Test. First equation models export intensity as function of $R \& D$ intensity and real exchange rate. In the second equation $R \& D$ intensity estimated as a function of export intensity and Herfindahl-Hirschman Index as competition variable. Causality test results show that there is unidirectional causal relationship from $R \& D$ intensity to export intensity. This finding supports the predictions of Posner's (1961) "technological gap theory" and Vernon's (1966) "product life cycle theory" related to the innovation and export relationship in Turkish Manufacturing Industry.
\end{abstract}

Key Words: Manufacturing Industry, Innovation, Export, Panel Data

Jel Classifacations: L60, O30, F10, C33

Geliş Tarihi / Received: 07.05.2017

Kabul Tarihi / Accepted: 31.08.2017

\footnotetext{
* Bu çalışma 6. Uluslararası Avrasya Ekonomileri Konferansında sunulan “Türk İmalat Sanayinde İhracat ve İnovasyon Arasındaki İlişki”" isimli bildiriden genişletilerek hazırlanmıştır.

${ }^{1}$ Prof. Dr., KTÜ, İ̈BF, İşletme Bölümü, spercin@ ktu.edu.tr, orcid.org/0000-0002-5840-7204.

${ }^{2}$ Y. Doç. Dr., RTEÜ, İIBBF, İşletme Bölümü, aykut.karakaya@erdogan.edu.tr, orcid.org/0000-0001-6970-3239.

${ }^{3}$ Doç. Dr., RTEÜ, İIBF, İktisat Bölümü, seymur.agazade@erdogan.edu.tr, orcid.org/0000-0001-5484-5189.
} 


\section{Giriş}

İnovasyon ve ihracat arasındaki ilişkinin yönü konusunda dış ticaret literatüründe farklı yaklaşımlar mevcuttur. İnovasyon daha önce var olmayan ve diş ticarete de konu olabilecek yeni malların, bunun yanı sıra teknolojik ürün veya bilginin ortaya çıkması biçiminde ifade edilebilir. Mevcut malların tüketici tercihlerine daha iyi hitap edecek tarzda, şekil ya da kalite bakımından farklılaştırılması da inovasyona ilişkindir. Aynı zamanda inovasyon, malların daha düşük maliyetle üretilmesine neden olacak üretim tekniklerinin geliştirilmesi, daha etkin yönetim, satış ve pazarlama anlayışının kullanılmasını da kapsar. İster yeni ürünlerin ortaya çıkması veya ürün farklılaştırması şeklinde, isterse de düşük maliyetli yöntemlerin kullanılması şeklinde olsun inovasyonun ihracatı artırıcı yönde etkilemesi beklenir. Posner (1961) tarafından geliştirilen "teknoloji açığı teorisi" ve Vernon (1966) tarafından geliştirilen "ürün dönemleri teorisi" de inovasyonun ihracatı artırıcı etkisini vurgular. Bu iki teori inovasyonun piyasa gücüne neden olduğunu ve ihracatı kolaylaştırdığını öngörür.

Posner (1961) dış ticareti ülkeler arasındaki teknoloji farkı ile açıklamakta ve bu görüş literatürde "teknoloji açığı teorisi”" olarak bilinmektedir. Posner'in (1961) çalışmasında sunduğu teorik tartışma benzer ekonomik koşullara sahip gelişmiş ekonomiler arasında sanayi ürünleri ticaretine ilişkindir. Bu ticaretin büyük kısmı genellikle gelişmiş ülkelerin yenilikçi firmaları tarafından gerçekleştirilen inovasyona dayandırılır. Burada patent ve fikri mülkiyet haklarına ilişkin yasaların yenilikçi firmalara daha fazla teşvik ve bu firmaların monopolistik özellikleri için koruma sağladığı da kabul edilir. Böylelikle teknik değişim veya bazı endüstrilerdeki gelişmelerin ticaret artışına neden olduğu düşünülür. Çünkü Posner'e göre, bir ülkede meydana gelen belirli bir teknik değişimden kaynaklanan karşılaştırmalı maliyet farklılıkları, inovasyonun diğer ülkelerce taklit edilmesine yetecek kadar bir öğrenme döneminde belirli malların ticaretini teşvik eder.

Vernon (1966) tarafından geliştirilen "ürün dönemleri teorisi” de inovasyon ve ihracat ilişkisini teknolojik açık teorisine benzer bir yaklaşımla açıklar. Fakat bu yaklaşım karşılaştırmalı maliyet farklılıklarına değil de inovasyon zamanlamasının, ölçek ekonomilerinin, bilgi eksikliğinin ve belirsizliğin dış ticaret üzerindeki etkisine vurgu yapar. "Ürün dönemleri teorisi", dış ticareti nitelikli emek ve ar-ge harcamalarının yüksek olduğu sanayileşmiş ülkelerde yeni ürünün ortaya çıktığı ilk aşama ve takip eden aşamalar yardımıyla açıklar. Başlangıç aşamasında ürünün standartlaştırılmadığı ve girdilerin, imalat sürecinin ve ürünün nihai şeklinin belirlenmesi geniş bir zaman aralığ gerektirdiğinden üretim ve ihracat düşük düzeydedir. Olgunlaşmış ürün olarak adlandırılan ikinci aşamada ise üretim ve ihracat artış gösterir. Standartlaşmış ürün safhasında ise, üretim düşük girdi maliyetleri nedeniyle az gelişmiş ülkelere kaydırılır ve ihracat da önemli ölçüde bu ülkeler tarafindan gerçekleştirilir. Krugman'ın (1979) “kuzey-güney modeli” de Vernon'un (1966) “ürün dönemleri teorisi” ile benzer 
bir sonuca ulaşır. Şöyle ki, inovasyonun yapıldığı yenilikçi kuzey ülkesi başlarda yeni ürünleri güney ülkesine ihraç eder. Sonraları söz konusu üretim teknolojisinin güney ülkesinde de mevcut olmasıyla düşük ücret rekabetinden dolayı kuzey ülkesi artık eski olan bu ürünleri güney ülkeden ithal edecektir. "Kuzey-güney modeli"nde, inovasyon mevcut malların üretiminde verimlilik artışı sağlanması şeklinde değil, yeni malların geliştirilmesi şeklinde ele alınır. Bu yeni mallarda monopol rantına neden olduğundan, modelde teknolojik gecikme ülkeler arasında ticaretin nedeni olarak ifade edilir.

Dış ticaretin endüstri içi etkilerini bir heterojen firma modeli çerçevesinde inceleyen Meltiz (2003) çalışmasında nedensellik ilişkisinin inovasyondan ihracata doğru olduğunu bulmuştur. Bu durum sadece verimlilikleri yüksek olan firmaların ihracat piyasasına girmelerine, düşük verimliliğe sahip firmaların ise bu piyasadan çıkmalarına ve sadece iç piyasaya yönelik üretim yapmalarına neden olur. Çünkü ihracat piyasasına yönelme taşıma, dağıtım, pazarlama gibi ilave maliyetlerin yüklenilmesini gerektirmektedir ki bunlara ancak yüksek verimliliğe sahip olan firmalar katlanabilir. Bernard ve Jensen (1999) de ihracatçı firmalarda ücret, verimlilik, sermaye yoğunluğu gibi değişkenlerin daha yüksek olduğunu ve dolayısıyla bu firmaların ihracat yaptıklarını ifade etmiştir.

İhracatın inovasyona veya ar-ge harcamalarına neden olduğu ise, Arrow'un (1962) “öğrenme teorisi”nden uyarlanmış olan ihraç ederek öğrenme (learning by exporting) fikrine dayanan inovasyon ve ar-ge'nin içselleştirildiği içsel büyüme modellerine dayanır (Romer, 1990; Grossman ve Helpman, 1991; Aghion ve Howitt, 1992). Buna göre firmaların uluslararası yapıda faaliyet göstermeleri veya dış ticarete açılmaları daha güçlü rekabetle karşılaşmalarına neden olur. Bu yapı yurtiçi piyasalardan daha farklı genellikle üst düzey standartlar gerektirir. Firmaların uluslararası ticarete açılmaları mevcut gelişmiş teknoloji ve bilgiye ulaşmalarını mümkün kılar. Yoğun rekabette ayakta kalmak, etkilerini hafifletmek veya rekabet üstünlüğü sağlamak ihraç ederek öğrenme etkisine neden olur ve firmaları inovasyona ve ar-ge faaliyetlerine yönlendirir. Bunun yanı sira Blalock ve Gertler'in (2004) de belirttiği gibi uluslararası piyasada yer almanın sağladığı öğrenme, bilgi, teknoloji, operasyonel etkinlik artışına neden olur ki bu da üretkenliği artırır. Yurtdışındaki bilgi birikiminin ihracat kanalıyla transfer edilmesi firmalara inovasyon veya üretim tekniklerini geliştirmeleri için daha geniş bir zemin hazırlar. Çünkü ihracatçı firmalar mallarına ilişkin daha geniş bir tüketici kitlesinin tercihlerini izleme olanağına sahip olurlar. Greenaway ve Kneller (2007) ise öğrenme ve rekabetin daha ileri verimlilik artışına neden olmasının ihracatçı firmanın maruz kaldığı rekabete bağlı olduğunu ve endüstriler arasındaki farklılıkların öğrenme etkisinin ortaya çıkması için önemli bir belirleyici olduğunu ifade eder. İnovasyonun ihracatı desteklemesi veya öğrenme etkisinin geçerli olmasının yanı sıra inovasyon ve ihracat ilişkisinin karşılıklı olmas1 da muhtemeldir. Aw, Roberts ve Xu (2011) da belirtildiği gibi ar-ge yatırımları firmanın ihracattan beklenen karlılığını artırır. Aynı zamanda ihracat da ar-ge yatırımlarının getirisine pozitif katkıda bulunur. 
Yukarıda ifade edildiği üzere, inovasyon ve ihracat ülkeler, endüstriler ve firmalar açısından uluslararası pazarlara açılıp yeni talepler oluşturma ve bunu sürekli kılmak yeni yetenekler kazanmayı gerektirmektedir. $\mathrm{Bu}$ açıdan Türk İmalat Sanayi'nde endüstrilerin inovasyon ve ihracat kabiliyeti ne düzeyde, gelişim ne yönde ve aralarındaki bağın nasıl olduğu soruları bu çalışmayla cevaplanmaktadır. $\mathrm{Bu}$ çalışma, Türk İmalat Sanayi endüstrilerinin 2008-2013 dönemleri yıllık verileriyle inovasyon yani ar-ge yoğunluğu ile ihracat yoğunluğu arasındaki nedensellik ilişkisini ortaya koymayı amaçlamaktadır. Araştırmanın analiz yöntemi içselliği dikkate alan İki Aşamalı Sistem Genelleştirilmiş Momentler Metodudur. Analizde nedensellik ilişkisi Wald Testiyle gerçekleştirilmiştir. Ar-ge yoğunluğu ve ihracat yoğunluğu arasındaki nedensellik ilişkisiyle Posner' in (1961) "teknoloji açığı teorisi”, Vernon'un (1966) "ürün dönemleri teorisi” veya Arrow'un (1962) "öğrenme teorisi"nden hangilerinin Türk İmalat Sanayi'nde geçerli olduğu ortaya çıkacaktır. Çalışmanın takip eden bölümleri şu şekilde düzenlenmiştir. İkinci bölümde araştırma veri ve değişkenleri, üçüncü bölümde araştırma tahmin yöntemi, dördüncü bölümde araştırma bulguları ve son bölümde sonuç ve öneriler yer almıştır.

\section{Araştırma Veri ve Değişkenleri}

Çalışmada Türk İmalat Sanayi NACE Rev.2 iki basamak endüstri sınıflamasına göre 24 endüstri kolunun ihracat ve inovasyon arasındaki nedensellik bağının ortaya konması amaçlanmıştır. Çalışmanın veri setini 24 imalat endüstri kolunun y1llık bilanço ve gelir tablosundan elde edilen bilgiler oluşturmuştur. Söz konusu veriler Türkiye İstatistik Kurumu'nun www.tuik.gov.tr ve TC Merkez Bankası'nın www.tcmb.gov.tr adresli internet sitelerinden derlenmiştir. Çalışma veri seti inceleme dönemi olarak 2008-2013 dönemlerini kapsayan 6 y1l için 24 imalat sanayii endüstri kolundan oluşan 144 gözlemden meydana gelmiştir. Aşağıdaki Tablo 1'de NACE Rev. 2 iki haneli sinıflama esasına göre Türkiye'deki İmalat Sanayii endüstrilerinde yer alan firmaların inceleme dönemindeki dağılımı sunulmuştur.

Tablo 1'deki firma dağılımlarına bakıldığında gıda, tekstil, metalik olamayan mineraller, giyim ve fabrikasyon metal ürünleri endüstrilerinde faaliyet gösteren firmaların toplam imalat sanayii firmalarının yarısından fazlasını oluşturduğu görülmektedir. Söz konusu bu endüstriler daha ziyade teknolojinin görece daha düşük düzeyde kullanıldığı daha geleneksel sanayii temsil etmektedir. Dolayısıyla, Türk İmalat Sanayi'nde üretim teknolojisinin ağırlıklı biçimde düşük ve orta yoğunlukta olduğu söylenebilir. Bu özelliğinden ötürü imalat sanayiinin dönüşümünde hayati rol oynayabilecek faktörler arasında inovasyon öne çıkmaktadır. Söz konusu dönüşümün etkin biçimde gerçekleşebilmesinde yeni pazarların önemi yadsınamaz. Bu ise, ya var olan pazarların geliştirilmesine ya da yeni pazarlara ulaşılmasıyla mümkün olacaktır. Bu yönüyle firmalar ve endüstriler açısından en etkili yeni pazarlara ulaşma yolu ihracat olarak karşımıza çıkmaktadır. $\mathrm{Bu}$ öneminden dolayı da, bu çalışmada inovasyon ve ihracat 
arasındaki nedensellik bağı incelenmiştir. İnovasyon ve ihracat arasındaki nedensellik ilişkisi modellerinde yer alan değişkenlerle ilgili açılamalar aşağıda sunulmuştur.

Tablo 1: Endüstri Kollarının Firma Dağılımları

\begin{tabular}{|c|c|c|c|}
\hline Kod & Endüstri Kolu & Sayı & $\%$ \\
\hline 10 & G1da Ürünlerinin İmalatı & 2.682 & 13,13 \\
\hline 11 & İçeceklerin İmalatı & 159 & 0,78 \\
\hline 12 & Tütün Ürünlerinin İmalatı & 66 & 0,32 \\
\hline 13 & Tekstil Ürünlerinin İmalatı & 2.778 & 13,59 \\
\hline 14 & Giyim Eşyalarının İmalatı & 1.719 & 8,41 \\
\hline 15 & Deri ve İlgili Ürünlerin İmalatı & 303 & 1,48 \\
\hline 16 & $\begin{array}{l}\text { Ağaç, Ağaç Ürünleri ve Mantar Ürünleri İmalatı } \\
\text { (Mobilya Hariç) }\end{array}$ & 378 & 1,85 \\
\hline 17 & Kağıt ve Kağıt Ürünleri İmalatı & 561 & 2,74 \\
\hline 18 & Kayıtlı Medyanın Basılması ve Çoğaltılması & 231 & 1,13 \\
\hline 19 & Kok Kömürü ve Rafine Edilmiş Petrol Ürünleri İmalatı & 87 & 0,42 \\
\hline 20 & Kimyasalların ve Kimyasal Ürünlerin İmalatı & 894 & 4,37 \\
\hline 21 & $\begin{array}{l}\text { Temel Eczacıllk Ürünleri ve Eczacılığa İliş̧kin } \\
\text { Malzemelerin İmalatı }\end{array}$ & 237 & 1,16 \\
\hline 22 & Kauçuk ve Plastik Ürünlerin İmalatı & 1.257 & 6,15 \\
\hline 23 & Diğer Metalik Olmayan Mineral Ürünlerin İmalat & 1.773 & 8,67 \\
\hline 24 & Ana Metal Sanayii & 1.230 & 6,02 \\
\hline 25 & $\begin{array}{l}\text { Fabrikasyon Metal Ürünleri İmalatı (Makine ve Teçhizat } \\
\text { Hariç) }\end{array}$ & 1.467 & 7,18 \\
\hline 26 & Bilgisayarların, Elektronik ve Optik Ürün İmalatı & 201 & 0,98 \\
\hline 27 & Elektrikli Teçhizat İmalatı & 723 & 3,54 \\
\hline 28 & Başka Yerde Sınıflandır. Makine ve Ekipman İmalatı & 1.254 & 6,14 \\
\hline 29 & Motorlu Kara Taşıtı, Treyler ve Yarı Treyler İmalatı & 900 & 4,40 \\
\hline 30 & Diğer Ulaşım Araçlarının İmalatı & 288 & 1,41 \\
\hline 31 & Mobilya İmalatı & 570 & 2,79 \\
\hline 32 & Diğer İmalatlar & 534 & 2,61 \\
\hline \multirow[t]{2}{*}{33} & Makine Ekipmanların Kurulumu ve Onarımı & 138 & 0,67 \\
\hline & Toplam İmalat Sanayii & 20.430 & 100 \\
\hline
\end{tabular}


İhracat, firmaların uluslararası aktivitelere girişte çok sık başvurduğu bir stratejidir (Wolff ve Peet, 2000). İhracatın ölçümü literatürde genelde üç boyutta ele alınmaktadır. İlki, firmaların ihracat yaptığı ülke sayısıyla ihracatın coğrafi bir alan olarak ölçümü, diğeri yurt dışı satışlardaki hız ve büyümedir. Üçüncüsü ise, ihracat yoğunluğudur (Leonidou vd. (2002); Zucchella vd., 2007). Bu çalışmada, ihracat Cavuşgil (1980), Ramaswamy vd. (1996), Wakelin (1998), Rasiah (2003), Özçelik ve Taymar (2004), Kirbach ve Schmiedeberg (2008) ve D’Angelo (2012) tarafından yapılan çalışmalarda olduğu gibi ihracatın toplam satışlara oranı olan ihracat yoğunluğu şeklinde ölçülmüştür.

İnovasyon doğası gereği çok boyutlu ve karmaşık olduğundan ölçümünde bir uzlaşı bulunmamaktadır. Literatürde inovasyon genelde üç biçimde ölçülmektedir. Bunlar; girdi göstergeleri (ar-ge harcamaları, ar-ge personeli gibi), ara çıktı göstergeleri (patentler, ticari markalar gibi) ve çıktı göstergeleridir (inovasyon sayısı, inovasyon türü, inovasyon devir hızı gibi). Bunlardan daha çok girdi ve çıktı göstergeleri kullanılmaktadır. Literatürde inovasyonu girdi göstergeleriyle ölçen çalışmalar arasında Wakelin (1998), Nassimbeni (2001), Özçelik ve Taymar (2004), Lopez Rodriguez ve Garcia Rodriguez (2005), Wignaraja (2007), Kirbach ve Schmiedeberg (2008), Harris ve Li (2009) ve D'Angelo (2012) tarafinda yapılan çalışmalar gösterilebilir. Bu çalışmada inovasyon girdi göstergelerinden, ar-ge yatırımının toplam aktiflere oranı olarak hesaplanan, ar-ge yoğunluğuyla ölçülmüştür.

İhracat modeline, ihracat döviz kurundan etkilendiğinden, Reel Döviz Kuru Endeksi (RDKE) ve inovasyon modeline inovasyon faaliyetleri yurt içi piyasa rekabetinden etkilendiğinden endüstri rekabet yoğunluğunu temsilen HerfindahlHirsckman Endeksi (HHI) dâhil edilmiştir.

\section{Araștırma Tahmin Yöntemi}

Panel veri analizi temel tahmin yöntemi Havuzlanmış En Küçük Kareler (HEKK) olmasına rağmen hata terimi ve bağımsız değişkenler arasında ilişkinin varlığı ile zaman içinde hata teriminin ardışık bağımlılı̆̆ını göz ardı ettiğinden HEKK ile tutarlı tahminler elde edilememektedir (Wooldrige, 2002: 256). Söz konusu bu sakıncaların giderilmesi amacıyla statik ve dinamik olmak üzere iki grupta sınıflanan panel veri analiz tahmincileri geliştirilmiştir.

Statik panel veri yöntemlerinde, cari dönemde oluşan iktisadi ve ticari davranışlar geçmiş dönemlerdeki deneyimlerden ve davranış biçimlerinden bağımsız kabul edilir. Hâlbuki iktisadi ve ticari davranışlarda, geçmiş deneyim ve davranışların etkisi oldukça önemlidir. Bu geçmiş deneyim ve davranışlar dikkate alındığında analize dinamik bir nitelik kazandırılmaktadır. Bunu dikkate alan panel veri yöntemleri dinamik panel veri modellerdir. Dinamik panel veri modellerinde ise, bağımlı değişkeni etkileyen faktörler arasında, bağımsız değişken veya değişkenlerin gecikmeli değerleri olabileceği gibi, bağımlı değişkenin gecikmeli değerleri de yer alabilmektedir. Bu yönüyle dinamik panel veri analizi, yatay kesit 
veya zaman serisi yöntemlerinin ortaya koyamadığı, mikro ve makro dinamikleri ortaya koyabilmektedir (Bond, 2002: 1).

Dinamik panel veri analizi, ekonometri literatüründe, ilk olarak Hansen (1982) tarafından geliştirilmiş olan Genelleştirilmiş Momentler Metodunu (GMM) temel almaktadir. Anderson ve Hsiao (1981 ve 1982) GMM'yi panel veriye uyarlamışlardır. Daha sonradan Arellano ve Bond (1991), Arellano ve Bover (1995) ve Blundell ve Bond (1998) tarafından bu yöntem geliştirilmiş ve panel veri yazınında yazarların isimleriyle birlikte anılan GMM ve Sistem Genelleştirilmiş Momentler Metodu (SGMM) olarak geçmiştir.

GMM tahmin yönteminde öncelikle modelin birinci farkı alınıp, fark modelin araç değişken matrisi kullanılarak dönüştürülmektedir. Daha sonra dönüştürülmüş model Genelleştirilmiş En Küçük Kareler (GEKK) ile tahmin edilmektedir. Veri seti dengeli olmayan panel veri ya da birim sayısının zamandan az olduğu panel verilerde birinci fark dönüşümü zayıf kalmaktadır. Bu durumda doğrusal (orthogonal) sapmaları kullanan SGMM kullanılmaktadır. Böylece SGMM ile etkin araç değişken tahmincisi elde edilebilmektedir (Baltagi, 2005: 148). SGMM'de GMM deki cari dönemden bir önceki dönemin farkının alınması yerine, değişkenlerin tüm olası gelecek değerlerinin ortalamalarının farkı alınmaktadır. Böylece, birinci farklar yönteminden kaynaklanan veri kaybının önüne geçilmektedir (Blundell ve Bond, 2000). Dolayısıyla, birimin zamandan büyük olduğu panel veri setlerinde değişkenler arasındaki doğrusal ilişkinin ortaya konmasında da SGMM tahmin yöntemi tercih edilir. Ĕger bağımsız değişkenler içsel değişkense, bu durumda içsellik problemini çözen İki Aşamalı SGMM'nin tahmincileri daha tutarlı ve sapmasız olacaktır. Çalışmada, Arellano ve Bover (1995) ve Blundell ve Bond (1998) tarafından önerilen iki Aşamalı SGMM tahmin yöntemi ile analizler gerçekleştirilmiştir. Ayrıca küçük örneklem tahminlerindeki standart hataların sapmasız olması için Windmeijer'in (2005) tarafından önerilen dirençli standart hatalar kullanılmıştır. Söz konusu dirençli standart hataların hesaplanmasında Roodman (2009) tarafindan yazılan kod kullanılmıştır. Nedensellik için Walt Testi yapılmıştır.

Çalışmanın ihracat modeli ve inovasyon modeli dinamik panel veri analiz yaklaşımıyla tahmin edilmiştir. İlgili ilişki aşağıdaki denklemlerde gösterilmiştir:

İhracat Yoğunluğ $u_{i t}=\beta_{1} \mathrm{I}$ hracat Yoğunluğ $u_{i t-1}+\beta_{2}$ Arge Yoğunluğ $u_{i t}+$ $\beta_{3}$ Arge Yoğunluğ $u_{i t-1}+\beta_{4}$ Arge Yoğunluğ $u_{i t-2}+\beta_{5} R D K E_{i t}+\varepsilon_{i t}$

$$
\begin{aligned}
& \text { Arge Yoğunluğ } u_{i t}=\beta_{1} \text { Arge Yoğunluğ } u_{i t-1}+\beta_{2} \mathrm{I} h \text { racat Yoğunluğ } u_{i t}+ \\
& \beta_{3} \mathrm{I} h r a c a t \text { Yoğunluğ } u_{i t-1}+\beta_{4} \mathrm{I} h r a c a t \text { Yognlug } u_{i t-2}+\beta_{5} H H I_{i t}+v_{i t}
\end{aligned}
$$

$i=1,2, \ldots, 24 \quad t=2008, \ldots, 2013$ 
Burada, $i$ ve $t$ sirasıyla endüstri kolu ve zamanı göstermektedir. İhracat ve ar-ge modellerindeki $t$ - 1 ve $t$ - 2 dönemlerini temsil eden değişkenler modellere dinamik özellik katan bağımlı ve bağımsız değişkenlerin gecikmeleridir. İhracat Yoğunluğ $u_{i t}$ endüstrilerin $\mathrm{t}$ dönemi ihracatın1, İhracat Yoğunluğ $u_{i t-1}$ t-1 dönemi ihracatını ve İhracat Yoğunluğ $u_{i t-2}$ t-2 dönemi ihracatıdır. Arge Yoğunluğ $u_{i t}$ endüstrilerin t dönemi ar-ge yatırımın1, Arge Yoğunluğ $u_{i t-1}$ t-1 dönemi ar-ge yatırımını ve Arge Yoğunluğ $u_{i t-2}$ t-3 dönemi ar-ge yatırımıdır. $R D K E_{i t} \mathrm{t}$ dönemi Türkiye'nin diş ticaretinde önemli paya sahip olan 38 ülkenin para biriminden oluşan sepete göre, Türk Lirasının nispi fiyat (ÜFE) etkilerinden arındırılarak elde edilen ağırlıklı ortalama değeridir. $H H I_{i t}$ endüstrilerin $\mathrm{t}$ dönemi rekabet yoğunluğu düzeyidir. $\varepsilon_{i t}$ ve $v_{i t}$ denklemlerin hata terimini göstermektedir.

\section{Araştırma Bulguları}

Araştırmanın bulguları endüstrilerin genel özellikleri ve değişkenler arasındaki ilişkilerin sunulduğu tanımlayıcı istatistikler, panel birim kök testi ve nedensellik tahmin sonuçlarının verildiği ihracat ve inovasyon modellerinden oluşan üç başlıkta aşağıda sunulmuştur.

\section{1. Tanımlayıcı İstatistikler}

Tablo 2'de değişkenlerin inceleme dönemindeki ortalama, standart sapma, minimum ve maksimum değerleri görülmektedir. Ortalamalardan yola çıkarak, endüstrilerde toplam satışların yaklaşık \%30'unun ihraç edildiği ve toplam varlıkların \%1'i dolayında ar-ge yatırımı yapılan piyasanın orta düzey rekabete sahip olduğu ifade edilebilir. TC Merkez Bankasının döviz politikasını belirlemek için kullandığı RDKE'nin ortalaması Türk Lirasının (TL) aşırı değerli olmadığını gösterir. Değişkenlerin minimum ve maksimum değerleri arasındaki farkın olması inceleme birimi olan endüstrilerin yaptıkları işlerdeki farklılıkların doğal bir sonucudur. RDKE'sinin minimum ve maksimum değerleri arasındaki fark TL'nin değerinin aşırı değerli olduğunu ifade etmez. Buradan, 2008-2013 dönemlerinde TL'nin düşük değerli, ar-ge yarımlarının yetersiz, yurt içi piyasada rekabetin orta düzeyde ve ihracatın orta yoğunlukta olduğu söylenebilir.

Tablo 2: Değişkenlerin Tanımlayıcı İstatistikleri

\begin{tabular}{|l|r|r|r|r|}
\hline Değişkenler & \multicolumn{1}{|c|}{ Ortalama } & S. Sapma & \multicolumn{1}{l|}{ Minimum } & \multicolumn{1}{l|}{ Maksimum } \\
\hline İhracat Yoğunluğu (\%) & 28,245 & 15,077 & 3,967 & 61,358 \\
\hline Ar-ge Yoğunluğu (\%) & 1,164 & 3,477 & 0 & 20,439 \\
\hline RDKE & 111,875 & 5,603 & 104,15 & 122,21 \\
\hline HHI $(0<$ HHI $\leq 1)$ & 0,226 & 0,213 & 0,007 & 0,809 \\
\hline
\end{tabular}

Tablo 2'de değişkenlerle ilgili sunulan bilgileri yıllar itibariyle gösteren aşağıdaki Grafik 1'den 4'e kadar bakıldığgnda, değişkenlerin yıllar itibariyle izlediği seyirler görülmektedir. 
Grafik 1: İhracat Yoğunluğu (\%)

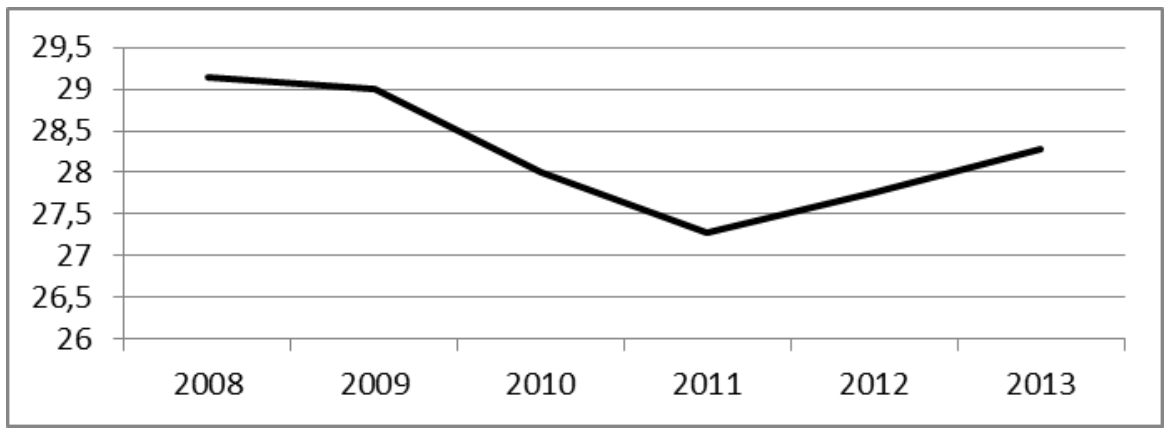

Grafik 1 endüstrilerin yıllar itibariyle ihracat yoğunluğunun eğiminde 2008'den 2011'e kadar düşüş ardından 2011'den sonra 2013'e kadar yükseliş kaydettiğini göstermektedir. İhracat yoğunluğu 2008'de yaklaşık \%30 seviyesinden düşerek 2011'de yaklaşık \%27'ye inmiş ve ardından artarak 2013'de \%28'e gelmiştir. İhracat yoğunluğunun biçimi ' $V$ ' şeklindedir. İhracat yoğunluğundaki bu azalışın küresel finansal krizin ardından geldiği ve sonrasında bu etkinin 2012 ve 2013 yıllarında nispeten attığı görülmektedir. Ancak, ihracat yoğunluğu seviyesi küresel finansal krizden önceki seviyesine ulaşamamıştır. Buradan, Türk İmalat Sanayi'nin ihracatta krizle birlikte küresel piyasalardaki daralmanın etkisini tam olarak atlatamadığını söylemek yanlış olmaz.

Grafik 2: Ar-ge Yoğunluğu (\%)

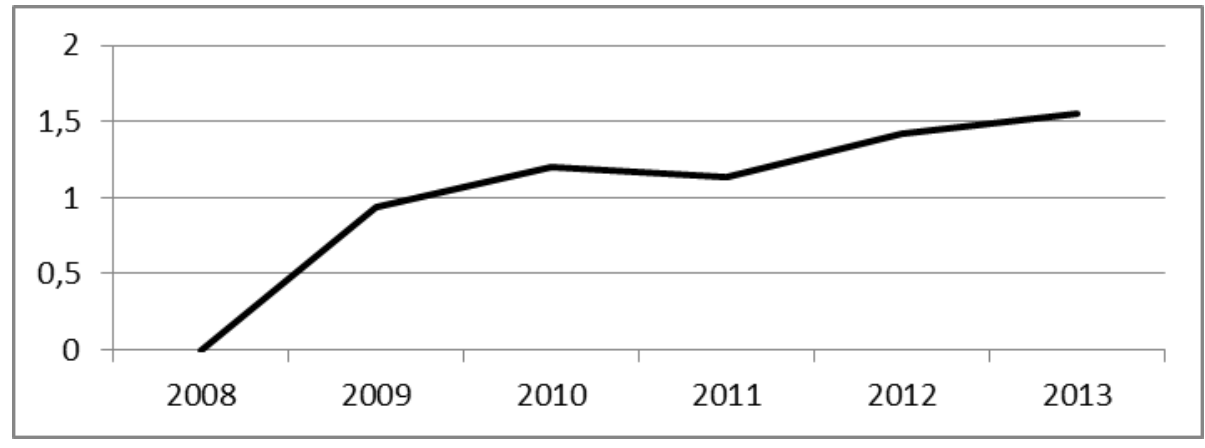

Grafik 2 incelendiğinde Türk İmalat Sanayi'nin ar-ge yoğunluğunda sabit olmasa da sürekli bir artış vardır. 2008 yılında ar-ge yoğunluğu neredeyse sıfırdır. Bunu takip eden y1llarda ar-ge yoğunluğu artarak süreklilik arz etmiş ve yaklaşık \%1,6 seviyesine yükselmiştir. Gelinen seviye düşük olmasına rağmen, bu hızlı artış hükümetin sektörel ve bölgesel kalkınma politikalarının yanında teknoloji yatırımlarına verdiği teşviklerin bir sonucu olduğu söylenebilir.

Aşağıdaki Grafik 3'de TC Merkez Bankasının döviz kuru politikası aracı olan reel döviz kuru endeksinin yıllar itibariyle nasıl bir eğilime sahip olduğu gösterilmektedir. TC Merkez Bankası reel döviz kuru endeksinin 120'nin üzerinde olmasını TL’nin aşırı değerli olduğunu kabul etmektedir. Reel döviz kuru 
endeksinin biçimi ters 'W' şeklindedir. Grafiğe bakıldığında sadece 2010 yılında TL'nin aşırı değerli diğer yıllarda ise nispeten düşük değerlendiği görülmektedir. Dolayısıyla, TL'nin değeri firmaların ihracatını zorlaştırmayıp, aksine ihracatı daha yapılabilir kılmıştır. Sonuç olarak, TC Merkez Bankası kur politikasının küresel finansal krizle birlikte firmaların ihracatını teşvik edici yönde seyrettiğini söylemek yanlış olmayacaktır.

Grafik 3: Reel Döviz Kuru Endeksi

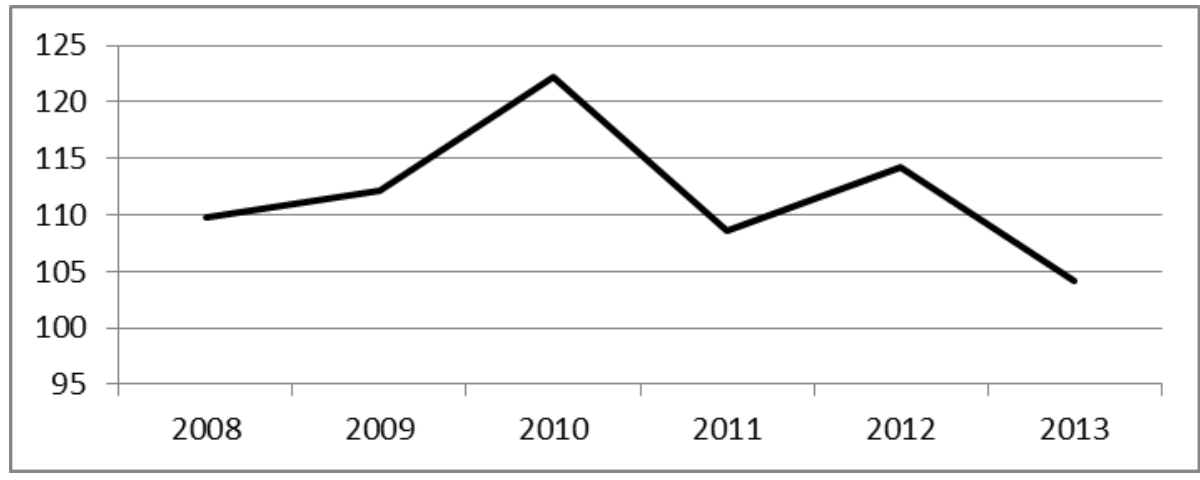

Grafik 4'de endüstrilerin rekabet yoğunluğu Herfindahl-Hirschman Endeksi (HHI) ile hesaplanmış ve 2009-2012 yılları itibariyle ortalamaları sunulmuştur. HHI 2009'dan 2012'ye kadar düzenli olarak düşüş olmuştur. HHI'daki bu düşüş piyasa yoğunluğunun azaldığını yani rekabette artış olduğunu ortaya koymaktadır. Yıllar itibariyle rekabette bu artış, 2012 yılında Türk İmalat Sanayi'nde piyasa rekabetini rekabetçi monopol ile tam rekabet piyasası sınırına taşımıştır. Yukarıdaki bulgular 1şığında, Türk İmalat Sanayi'nde ihracat yoğunluğunun azaldığ düşük değerlendiği söylenebilir.

Grafik 4: Endüstrilerin Rekabet Yoğunluğu (HHI)

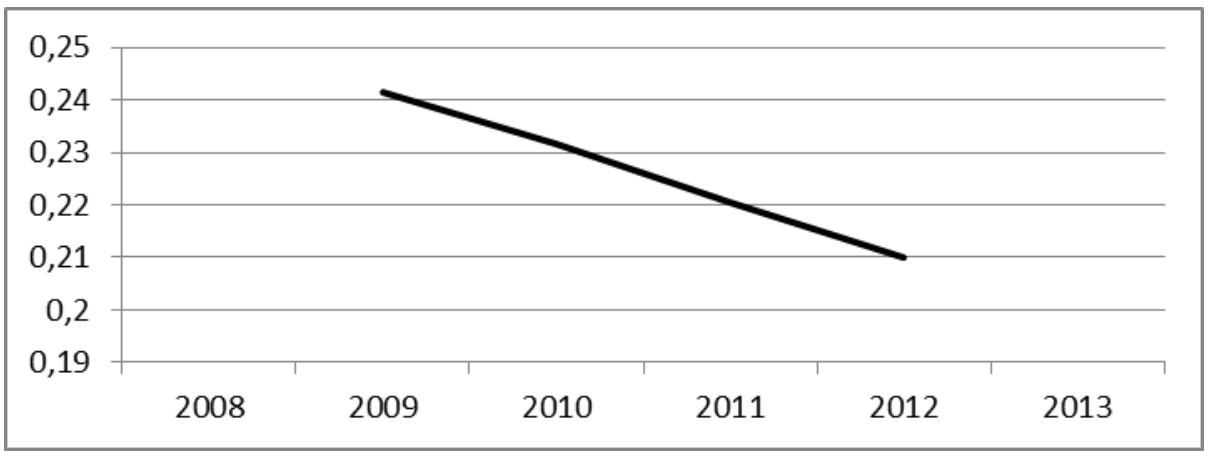

Tablo 3'de değişkenlerin korelasyonları yer almaktadır. $\mathrm{Bu}$ ilişkiler incelendiğinde, ihracat yoğunluğu ile ar-ge yoğunluğu arasında pozitif bir ilişki vardır. İlaveten, rekabet yoğunluğu ile ihracat ve ar-ge arasında negatif bir ilişki hesaplanmıştır. Diğer değişkenler arası ilişkiler istatistiksel olarak anlamlı 
değildir. İhracat ve ar-ge arasında pozitif ilişki ar-ge'nin yüksek olduğu endüstrilerde ihracatın da yüksek olduğunu gösterir, bunun tersi de geçerlidir. Rekabet yoğunluğu ile ihracat ve ar-ge arasında ise negatif ilişki vardır. Rekabet yoğunluğunun artması daha az sayıda firmanın piyasaya hakim olduğunu ve rekabetin düşük olduğunu göstermektedir. Dolayısıyla, yurt içi piyasada rekabetin yüksek olduğu endüstrilerde ihracat ve ar-ge yüksek, yurt içi piyasada rekabetin düşük olduğu endüstrilerde ise ihracat ve ar-ge düşüktür. Böylece, Türk İmalat Sanayi'nde ihracat, ar-ge ve piyasa rekabeti arasındaki ilişkinin pozitif olduğu ortaya çıkmaktadır.

Tablo 3: Değişkenlerin Korelasyonları

\begin{tabular}{|l|l|l|l|}
\hline Değişkenler & İhracat Yoğunluğu & Ar-ge Yoğunluğu & RDKE \\
\hline İhracat Yoğunluğu & 1 & & \\
\hline Ar-ge Yoğunluğu & $0,265^{* * *}$ & 1 & \\
\hline RDKE & 0,007 & 0,013 & 1 \\
\hline HHI & $-0,429^{* * *}$ & $-0,079^{*}$ & 0,011 \\
\hline
\end{tabular}

Not: ${ }^{*}$ ve ${ }^{* * *}$ sirasıyla 0.10 , ve 0.01 düzeyinde istatistiksel anlamlılıkları göstermektedir.

\section{2. Panel Birim Kök Testi}

Zaman serisi analizleri ve panel veri analizlerinde sahte regresyonla karşılaşmamak için öncelikle değişkenlerin birim kök testleri aracılığıyla durağanlıkları tespit edilir. Panel verilerin birim kök testi için geliştirilmiş panel veriye özgü birim kök testleri mevcuttur. Panel veri birim kök testleri birinci ve ikinci kuşak testler olmak üzere iki başlıkta sınıflandırılırlar. Birinci kuşak panel birim kök testleri birimlerin bağımsız olduğunu, ikinci kuşak panel birim kök testleri ise birimlerin bağımlı olduğunu varsaymaktadır. Birinci kuşak panel birim kök testleri, kendi içerisinde iki kısıma ayrılırlar. Bunlardan, ilk gruptakiler otokorelasyonun birimden birime değişmediğini, buna karşın ikinci grup ise değiştiğini varsaymaktadır. Dolayısıyla ilk gruptakiler ortak otokorelasyon, ikinci gruptakiler ise bireysel otokorelasyon varsayımı dahilinde hesaplanırlar.

Panel birim kök testinin hesaplanmasına geçmeden önce hangi tür birim kök testleriyle durağanlığın ele alınmasının uygun olacağına karar verilmesi amacıyla birimlerin bağımsızlığının incelenmesi gerekir. Çalışmada ihracat ve ar-ge modellerinde birimlerin bağımsızlı̆̆ Friedman (1937) birimlerin bağımsızlığ testi ile gerçekleştirilmiştir. Friedman (1937) birimlerin bağımsızlığı testi, Spearman Sira Korelasyon katsayısı kullanılarak hesaplanan parametrik olmayan bir testtir. Friedman (1937) birimlerin bağımsızlığı testi ihracat modeli için $r=$ 6,071 ve anlamlılık düzeyi 0,999 ve ar-ge modeli için $r=4,200$ ve anlamlılık düzeyi 1,000'dir. Friedman (1937) testi sonucunda birimlerin bağımsız olduğuna ulaşılmıştır. 
Çalışmanın birimleri imalat sanayiindeki sektörler olduğundan farklı sektörlerde yapılan işin doğası gereği farklılaşacağı kabulünden hareketle otokorelasyonun birimler için değişeceği varsayımının daha isabetli olacağına karar verilmiştir. Böylece birinci kuşak panel birim kök testlerinden ikinci grup testleriyle değişkenlerin birim kök testi gerçekleştirilmiştir. İkinci grup panel birim kök testleri Im, Peseran ve Shin (2003) (IPS) testi ve Fisher testlerinden oluşmaktadır. IPS testi tek bir istatistiğe Fisher testleri ise birden fazla istatistiğin kombinasyonları üzerine kuruludur. IPS testi parametrik Fisher testleri ise parametrik olmayan testlerdir (Yerdelen Tatoğlu, 2012:219). Fisher testleri küçük örneklemle çalışmaya IPS testine göre daha yatkın olduğundan çalışmada Fisher testleri ile değişkenlerin birim kök testi gerçekleştirilmiştir. Fisher panel birim kök testleri Fisher ADF ve Fisher Philips-Perron (PP) olmak üzere ikiye ayrılır. Fisher ADF testi zaman serileri birim kök testlerinden ADF birim kök testini her birime uygulamaktadır. Benzer biçimde, Fisher PP testi de zaman serileri birim kök testlerinden biri olan Philips-Perron (PP) birim kök testini her birime uygulanmaktadır (Choi, 2001).

Tablo 5: Fisher Phillips-Perron Panel Birim Kök Testi Sonuçları

\begin{tabular}{|l|l|l|}
\hline Değişkenler & Düzeltilmiş Ters $\boldsymbol{X}^{2}$ & Durum \\
\hline İhracat Yoğunluğu $_{\mathrm{t}}$ & $2,010^{* * *}$ & Düzey durağandır \\
\hline Ar-ge Yoğunluğu & $1,736^{* *}$ & Düzey durağandır \\
\hline $\mathrm{HHI}_{\mathrm{t}}$ & $36,880^{* * *}$ & Düzey durağandır \\
\hline $\mathrm{RDKE}_{\mathrm{t}}$ & $3,746^{* * *}$ & Düzey durağandır \\
\hline
\end{tabular}

Not: ${ }^{* * *}$ ve ${ }^{* * *}$ sirasıyla $0.10,0.05$ ve 0.01 düzeyinde istatistiksel anlamlılıkları göstermektedir.

Fisher PP testinin $\mathrm{P}, \mathrm{Z}, \mathrm{L}^{*}$ ve $\mathrm{P}_{\mathrm{m}}$ istatistiklerinin tamamı aynı sonucu verdiğinden bunlardan sadece $\mathrm{P}_{\mathrm{m}}$ istatistiğini gösteren Düzeltilmiş Ters $X^{2}$ değerleri yukarıdaki Tablo 5'de raporlanmıştır. $\mathrm{P}_{\mathrm{m}}$ istatistiğine göre çalışmanın ihracat, ar-ge, rekabet ve reel döviz kuru endeksi değişkenlerinin tamamının original düzeylerinde birim kök içermediği, yani değişkenlerin original düzeylerinde durağan olduğu sonucuna varılmıştır. Original düzeylerinde tüm değişkenler durağan olduğundan ihracat ve ar-ge modelleri değişkenlerin original düzeyinde sahte regresyon tehlikesiyle karşılşamadan tahmin edilebileceği sonucuna varılmıştır.

\section{3. İhracat ve İnovasyon Arasındaki Nedensellik İlișkisi}

Aşağıdaki Tablo 6 ve 7'de sunulan İki Aşamalı SGMM tahmincisinden elde edilen bulgularda, modellerin genel anlamlılığını gösteren Wald İstatistikleri sonuçlarına bakıldığında, tüm modeller anlamlıdır. Modellerle ilgili, birinci mertebe otokorelasyonun varlığının testinde Arellano ve Bond'un otokorelasyon (AR1) testi anlamlı ve ikinci mertebe otokorelasyon (AR2) testi anlamsizdir. Bu testlere göre, modellerde birinci mertebe otokorelasyonun olduğu buna karşın, ikinci mertebe otokorelasyonun olmadığı bulunmuştur. Bu bulgu, modellerdeki 
bağımsız değişkenlerin ikinci gecikmeleri olan araç değişkenlerin doğru tespit edildiği anlamına gelmektedir. Ardından, modellerden elde edilen araç değişkenlerin geçerliliği için yapılan dirençsiz Sargan Testi anlamlı iken, dirençli Hansen Testi ve dirençli Fark Hansen Testi anlamsızdır. Dirençsiz Sargan Testi dışındaki dirençli testler, İki Aşamalı Sistem GMM yöntemiyle yapılan performans modellerinin tahmininde kullanılan araç değişkenler regresyonunda kullanılan araç değişkenlerin geçerli ve modellerin uygun olduğunu göstermektedir. İhracat ve inovasyon modelleri genel anlamlılık, otokorelasyon ve araç değişkenler regresyonu ile ilgili koşulların tamamını sağlamaktadır.

Aşağıdaki Tablo 6'da ihracat modelinde tüm bağımsız değişkenlerin anlamlı olduğu görülmektedir. Bağımsız değişken ihracat yoğunluğunun bir dönem gecikmesinin bağımlı değişken ihracat yoğunluğuna pozitif yönlü etkisi, kazanılan ihracat deneyiminin daha sonraki ihracatı desteklediği anlamına gelebilir. Dolayısıyla, Türk İmalat Sanayi firmalarının, yurt dışında kazandığı ihracat deneyiminden öğrendikleriyle takip eden dönem ihracatlarını daha da artırabildiği söylenebilir. İhracat yoğunluğuna reel döviz kuru endeksinin pozitif yöndeki etkisi ise, TC Merkez Bankası tarafından belirlenen düşük değerlenen TL'nin cari dönem ihracatını teşvik ettiği anlamına gelir. Bağımsız değişkenlerden ar-ge yoğunluğunun bir ve iki dönem gecikmesinin ihracat yoğunluğuna etkisi pozitif, cari dönem ar-ge yoğunluğunun ise negatiftir. Önceki dönemlerde yapılan ar-ge harcamalarının ticarileşmesiyle ihracatın arttığ harcamalarının ticarileşmesi için yeterli zaman geçmediğinden ihracatı azalttığı görülmüştür.

Tablo 6: İhracat Modeli Tahmin Sonuçları

\begin{tabular}{|c|c|}
\hline \multirow{2}{*}{ Bağımsız Değişkenler } & Bağımlı Değișken \\
\hline & İhracat Yoğunluğ $u_{t}$ \\
\hline İhracat Yoğunluğut-1 & $0.792^{* * * *}[0.063]$ \\
\hline Ar-ge Yoğunluğu & $-2.408^{* *}[1.008]$ \\
\hline Ar-ge Yoğunluğ $u_{t-1}$ & $1.883^{* * * *}[0.502]$ \\
\hline Ar-ge Yoğunluğ $u_{t-2}$ & $1.644^{*}[0.860]$ \\
\hline Reel Döviz Kuru Endeksi & $0.044^{* * * *}[0.016]$ \\
\hline Wald İstatistiŏ $i$ & $12265^{* * * *}$ \\
\hline AR1 Testi & $-2.08^{* *}$ \\
\hline AR2 Testi & -0.87 \\
\hline Sargan Testi & $50.43^{* * * *}$ \\
\hline Hansen Testi & 20.31 \\
\hline Fark Hansen Testi & 6.23 \\
\hline Wald Testi & $14.53^{* * * *}$ \\
\hline
\end{tabular}

Not: ${ }^{*}{ }^{* *}$ ve ${ }^{* * *}$ sirasıyla $0.10,0.05$ ve 0.01 düzeyinde istatistiksel anlamlılıkları göstermektedir. Köşeli parantez içindeki değerler düzeltilmiş standart hatalardir.

Ar-genin yani inovasyonun ihracatın nedeni olup olmadığıyla ilgili ar-ge yoğunluğu değişkenlerinin önündeki katsayılar Walt Testiyle sınanmıştır. Test sonucunda \%1 anlamlılık düzeyinde boş hipotez ret edilmiştir. Bu sonuç, ar-ge 
yoğunluğunun yani inovasyonun ihracatın nedeni olduğu anlamına gelmektedir. Türk İmalat Sanayi'nde inovasyonun ihracatın nedeni olduğu bulgusu, bu ilişkiyi ele alan öncü araştırmalardan Hirsch ve Bijaoui (1985)'nin İsrail, Brouwer ve Kleinknecht (1996)'in Hollanda, Zhao ve Li (1997)'nin Çin ve Gourlay ve Seaton (2004)'nın Büyük Britanya için elde ettikleri sonuçları destekleyici niteliktedir.

Tablo 7'deki inovasyon modelindeki bağımsız değişkenlerden ihracat yoğunluğu değişkenleri haricindeki diğer değişkenler anlamlıdır. Bağımlı değişken ar-ge yoğunluğunu bağımsız değişkenlerden ar-ge yoğunluğunun bir dönem gecikmesi pozitif ve HHI endüstri rekabet yoğunluğu değişkeni negatif yönde etkilemiştir. $\mathrm{Bu}$ bulgu, daha önce yapılan ar-ge deneyiminin sonraki dönem ar-geyi artırdığını göstermektedir. Bu durumda bir dönem önceki ar-ge harcamalarının ticarileşip firmaları yeni ar-ge yatırımlarını teşvik ettiği söylenebilir. Rekabet yoğunluğunun ar-ge yoğunluğunu negatif yönde etkilemesi ise, piyasadaki rekabet düzeyindeki artışın ar-ge harcamalarını arttığı anlamına gelmektedir.

İhracatın Ar-ge'nin yani inovasyonun nedeni olup olmadığıyla ilgili ihracat yoğunluğu değişkenlerinin önündeki katsayılara Walt Testi uygulanmıştır. Test sonucunda $\% 5$ anlamlılık düzeyinde boş hipotez ret edilememiştir. Bu sonuç, ihracatın Ar-ge'nin yani inovasyonun nedeni olmadığı anlamına gelmektedir.

Tablo 7: İnovasyon Modeli Tahmin Sonuçları

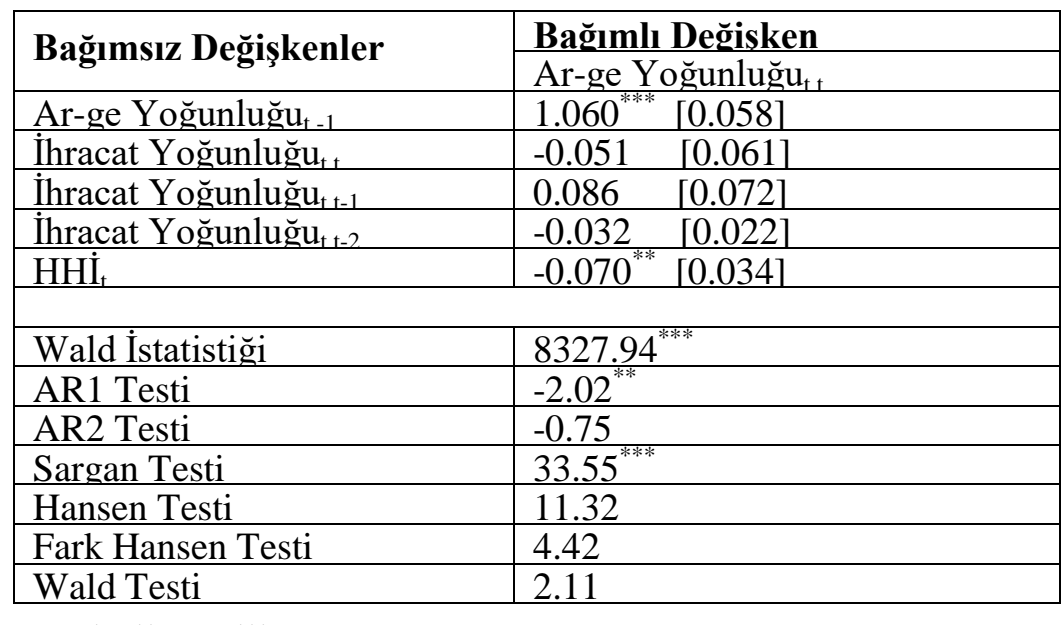

Not: ${ }^{*},{ }^{* *}$ ve ${ }^{* * *}$ sirasiyla $0.10,0.05$ ve 0.01 düzeyinde istatistiksel anlamlılıkları göstermektedir. Köşeli parantez içindeki değerler düzeltilmiş standart hatalardir.

\section{Sonuç ve Öneriler}

İnovasyon ve ihracat arasındaki ilişkinin yönü konusunda dış ticaret literatüründe farklı yaklaşımlar mevcuttur. Posner (1961) tarafından geliştirilen "teknoloji açığı teorisi" ve Vernon (1966) tarafından geliştirilen "ürün dönemleri teorisi” inovasyonun ihracatı artırıcı etkisini vurgular. Bu iki teori inovasyonun piyasa gücüne neden olduğunu ve ihracatı kolaylaştırdığını öngörür. İhracatın 
inovasyona veya ar-ge harcamalarına neden olduğu ise, Arrow'un (1962) “yaparak öğrenme” görüşünün ihraç ederek öğrenmeye uyarlandığı içsel büyüme modellerine dayanır. Bazı çalışmalar ise, ihracat ve inovasyon arasındaki ilişkinin çift yönlü olduğu yönünde teorik temeller sunmaktadır. Uygulamalı çalışmalar ise firma düzeyinde olduğu gibi endüstri ve ülke düzeyinde de yapılmaktadır. $\mathrm{Bu}$ çalışmada, Türk İmalat Sanayi endüstrilerinin 2008-2013 dönemleri yıllık verileriyle inovasyon ile ihracat arasındaki nedensellik ilişkisi araştırılmıştır. Analiz yöntemi içselliği dikkate alan İki Aşamalı Sistem Genelleştirilmiş Momentler Metodu ve Wald Testidir.

Çalışmadan elde edilen tanımlayıcı bulgulara göre; Türk İmalat Sanayi'nde, ar-ge yarımları yetersiz, yurt içi piyasa rekabetçi monopolistik karakterde ve ihracat görece düşük düzeydedir. Buna karşın, yıllar itibariyle ihracatın, ar-genin, yurt içi piyasa rekabetinin giderek arttığı görülmektedir. Küresel finansal krize rağmen, bu olumlu gelişmelerde sektörün dinamizminin yanında uygulanan ekonomi ve teşvik politikaları etkili olduğu düşünülmektedir.

İhracat modeli için tahmin sonuçlarına göre; kazanılan ihracat deneyiminin sonraki ihracatı desteklediği, dolayısıyla bilgi sağlayarak ihracatı motive ettiği görülmüştür. İhracatın önceki dönemlerde yapılan inovasyonun ticarileşmesiyle arttığ1, buna karşın ilgili dönemde azaldığı görülmüştür. Aynı döneme ait inovasyonun negatif etkisi ticarileşme veya yeni ürünün piyasaya tanıtılması ve kabul edilmesi için gerekli süreden kaynaklanabilir. Ayrıca, düşük değerli TL ile ihracat desteklenmiştir.

İnovasyon modelinde; bir dönem önceki inovasyonun firmaları yeni ar-ge yatırımlarına teşvik ettiği ve rekabetin inovasyonu desteklediği tespit edilmiştir. $\mathrm{Bu}$ durum, rekabetin firmaları inovasyon yatırımı yapmaya yönlendirdiği anlamına gelir. Firmaların inovasyona yönelmesindeki amaç rekabetten korunmak veya piyasa gücü elde etmektir. Artan yurt içi piyasa rekabetinin üstesinden gelmenin bir aracı olarak, Türk İmalat Sanayi'nde firmaların inovasyona yöneldikleri, dolayısıyla Neoklasik iktisadın rekabet ve inovasyon ilişkisine dair görüşüne uyan davranış şekli gösterdikleri söylenebilir.

Nedensellik testi bulgularına göre, inovasyon ihracatın nedeni, buna karşın ihracat inovasyonun nedeni değildir. Nedenselliğin yönü tek taraflı ve inovasyondan ihracata doğrudur. Türk İmalat Sanayi'nde inovasyon faaliyetleriyle ihracatın artırılabildiği tespit edilmiştir. Dolayısıyla çalışma bulguları, Posner'in (1961) “teknoloji açığı teorisi” ile Vernon'un (1966) “ürün dönemleri teori”lerindeki inovasyon ve ihracata ilişkin öngörülerinin Türk İmalat Sanayi içinde geçerli olduğunu destekleyici niteliktedir. Buna karşın çalışma sonuçları ihracatın inovasyonu artırdığını öneren, Arrow'dan (1962) uyarlanmış ihracat yaparak öğrenme görüşünü destekleyici nitelikte değildir. Böylece, hayata geçirilecek etkin inovasyon politikalarıyla Türk İmalat Sanayi'nde ihracatın artırılabileceği buna karşın, uygulanacak ihracat politikalarıyla Türk İmalat Sanayi'nde inovasyonun artırılamayacağını ileri sürmek yanlış olmayacaktır. 
Ar-ge politikasıyla teknolojinin sürekli olarak iyileştirilmesi ve yenilenmesi benimsendiğinde Türkiye'nin yurt dişı piyasalarda rekabet üstünlüğü sağlamayı sürdürecektir. Rekabet üstünlügüünün elde edilmesi ve güçlendirilmesi kur politikalarından ziyade inovasyona daha fazla ağırlık verilmesi ile mümkündür. $\mathrm{Bu}$ nedenle yüksek teknolojiye dayalı üretime ve ihracata geçilmesi desteklenmelidir. Uygulanacak ar-ge faaliyetleri sonucunda geliştirilen ürün ve süreçlerle Türkiye'nin uluslararası rekabet gücü artacaktır. Böylece, ihracat muhtemelen döviz kurlarındaki dalgalanmalardan daha az etkilenecektir. Dolayısıyla, Türkiye'nin uluslararası rekabetteki maliyet avantajı kur politikaları değil, inovasyon ve teknoloji politikaları temelinde olmalıdır.

Çalışma inovasyonun ihracatı artırdığını göstermektedir. İsabetli politikaların kurgulanması ve uygulanabilmesi amaciyla hangi endüstrilerde inovasyonun etkili olacağının bilinmesi büyük önem taşımaktadır. Bu doğrultuda, inovasyon ve ihracat arasındaki bağın daha iyi anlaşılabilmesi amacıyla inovasyonun içeriği, inovasyonun türü ve teknoloji yoğunluğunu dikkate alan araştırmalar yapılabilir.

\section{Kaynakça}

Aghion, P. ve Howitt. P. (1992), "A Model of Growth through Creative Destruction", Econometrica, 60 (2), 323-351.

Anderson, T. W. ve Hsiao, C. (1981), "Estimation of Dynamic Models with Error Components", Journal of the American Statistical Association, 76, 375, 598606.

Anderson, T. W. ve Hsiao, C. (1982), "Formulation and Estimation of Dynamic Models Using Panel Data”, Journal of Econometrics, 18, 47-82.

Arellano M. ve Bond, S. (1991), "Some Tests of Specification for Panel: Monte Carlo Evidence and An Application to Employment Equations", Review of Economic Studies, 58, 277-297.

Arellano M. ve Bover, O. (1995), "Another Look at the Instrumental Variable Estimation of Error-Components Models", Journal of Econometrics, 68, 2951 .

Arrow, K. J. (1962), "The Economic Implications of Learning by Doing", The Review of Economic Studies, 29 (3), 155-173.

Aw, B. Y., M. J. Roberts ve D. Yi Xu. (2011), "R\&D Investment, Exporting, and Productivity Dynamics", American Economic Review, 101(4), 1312-44.

Baltagi, B. H. (2005), Econometric Analysis of Panel Data, Third Edition, John Wiley\&Sons, Ltd., England.

Bernard, A. B. ve B. Jensen, J. (1999), "Exceptional Exporter Performance: Cause, Effect, or Both?”, Journal of International Economics, 47, 1-25. 
Blalock, G. ve Gertler, P. J. (2004), “Learning from Exporting Revisited in A Less Developed Setting”, Journal of Development Economics, 75 (2), 397-416.

Blundell R. ve Bond S. (1998), "Initial Conditions and Moment Restrictions in Dynamic Panel Data Models", Journal of Econometrics, 87, 115-143.

Blundell, R. ve Bond, S. (2000), "GMM Estimation with Persistent Panel Data: An Application to Production Functions", Econometric Reviews, 19, 321-340.

Bond, S. (2002), "Dynamic Panel Data Models: A Guide to Micro Data Methods and Practice", CEMMAP Working Paper, No: Cwp0209, 1-36.

Brouwer, E. ve Kleinknecht, A. (1996), "Determinants of Innovation: A Microeconometric Analysis of Three Alternative Innovation Output Indicators", In: Kleinknecht, A. (ed.). Determinants of Innovation, London: Macmillan Press Ltd., 99-125.

Choi, I. (2001), "Unit Root Tests for Panel Data", Journal of International Money and Finance, 20, 249-272.

Çavuşgil, S. T. (1980), “On the Internationalisation Process of Firms”, European Research, 8(6), 273-281.

D’Angelo, A. (2012), “Innovation and Export Performance: A Study of Italian high-tech SMEs", Journal of Management and Governance, 16, 393-423.

Greenaway, D. ve R. Kneller. (2007), "Industry Differences in the Effect of Export Market Entry: Learning by Exporting?", Review of World Economics, 143(3), 416-432.

Grossman, G. M. ve Helpman, E. (1991), "Endogenous Product Cycles", The Economic Journal, 101 (408), 1214-1229.

Gourlay, A.R. ve Seaton, J. S. (2004), "UK Export Behavior at the Firm Level", Economic Issues, 9(2), 3-19.

Friedman, M. (1937), "The Use of Ranks to Avoid the Assumption of Normality Implicity in the Analysis of Variance", Journal of the American Statistical Association, 32, 675-701.

Hansen, L. P. (2002), "Large Sample Properties of Generalized Method of Moments Estimators", Econometrica, 50, 1029-1054.

Harris, R. ve Li, Q. C. (2009), "Exporting, R\&D, and absorptive capacity in UK establishments", Oxford Economic Papers, 61(1), 74-103.

Hirsch, S. ve Bijaoui, I. (1985), "R\&D Intensity and Export Performance: A Micro View", Review of World Economics, 121, 238-251.

Hsiao, C. (2003), Analysis of Panel Data, Second Edition, Cambridge University Press, United Kingdom. 
Im, K. S., Pesaran, M. H. ve Shin, Y. (2003), "Testing for unit roots in heterogeneous panels", Journal of Econometrics, 115, 53-74.

Kirbach, M. ve Schmiedeberg, C. (2008), "Innovation and Expert Performance: Adjustment and Remaining Differences in East and West German Manufacturing", Economics of Innovation and New Technology, 17(5), 435457

Krugman, P. (1979), "A Model of Innovation, Technology Transfer, and the World Distribution of Income”, Journal of Political Economy, 87 (2), 253-266.

Leonidou, L. C., Katsikeas, C. S. ve Samieec, S. (2002), "Marketing Strategy Determinants of Export Performance: A Meta-Analysis". Journal of Business Research, 55(1), 51-67.

Lopez Rodriguez, J. ve Garcia Rodriguez, R. M. (2005), “Technology and Export Behaviour: A Resourcebased View Approach”, International Business Review, 14(5), 539-557.

Melitz, M. J. (2003), "The Impact of Trade on Intra-Industry Reallocations and Aggregate Industry Productivity”, Econometrica, 71 (6), 1695-1725.

Nassimbeni, G. (2001), "Technology, Innovation Capacity, and the Export Attitude of Small Manufacturing Firms: A Logit/Tobit Model”, Research Policy, 30(2), 245-262.

Özçelik, E. ve Taymar, E. (2004), "Does Innovativeness Matter for International Competitiveness in Developing Countries", Research Policy, 33(3), 409-424.

Posner, M. V. (1961), "International Trade and Technical Change", Oxford Economic Papers, New Series, 13 (3), 323-341.

Ramaswamy, K., Kroeck, K. G. ve Renforth, W. (1996), "Measuring the Degree of Internationalisation of A Firm: A Comment", Journal of International Business Studies, 27(1), 167-177.

Rasiah, R. (2003), "Foreign Ownership, Technology and Electronics Exports from Malaysia and Thailand", Journal of Asian Economics, 14(5), 785-811.

Romer, P. M. (1990), "Endogenous Technological Change", Journal of Political Economy, 98 (5), Part 2, 71-102.

Roodman, D. (2009), "How to Do xtabond2: An Introduction to "Difference" and "System" GMM in Stata," The Stata Journal, 9(1), 86-136.

Yerdelen, T. F. (2012), İleri Panel Veri Analizi Stata Uygulamalı, Beta Yayıncılık, İstanbul.

Vernon, R. (1966), "International Investment and International Trade in the Product Cycle", The Quarterly Journal of Economics, 80, 190-207. 
Walkelin, K. (1998), "Innovation and Export Behavior at the Firm Level", Research Policy, 26, 829-841

Wignaraja, G. (2007), "Foreign Ownership, Technological Capabilities and Clothing Exports in Sri Lanka", Journal of Asian Economics, 19(1), 29-39.

Windmeijer, F. (2005), "A Finite Sample Correction for the Variance of Linear Efficient Two-Step GMM Estimator”, Journal of Econometrics, 126(1), 25-51.

Wolff, J. A. ve Pett, T. L. (2000), "Internationalisation of Small Firms: An Examination of Export Competitive Patterns, Firm Size, and Export Performance", Journal of Small Business Management, 38(2), 34-47.

Wooldridge, J. M. (2002), Econometric Analysis of Cross Section and Panel Data, The MIT Press, England.

Zhao, H. ve Li, H. (1997), "R\&D and Export: An Empirical Analysis of Chinese Manufacturing Firms", Journal of High Technology Management Research, 8(1), 89-106.

Zucchella, A., Palamara, G. ve Denicolai, S. (2007), "The Drivers of The Early Internationalisation of the Firm", Journal of Word Business, 42(3), 268-280. 